\title{
Mobile Phone Network and Migration: Evidence from Myanmar
}

\author{
Riccardo Ciacci I rciacci@comillas.edu \\ Jorge García-Hombrados I jorge.garciah@uam.es \\ Ayesha Zainudeen I ayesha@lirneasia.net
}

This working paper has been approved for release by: Mikko Myrskylä (sekmyrskyla@demogr.mpg.de),

Head of the Laboratory of Population Health, the Laboratory of Fertility and Well-Being, and the Research Group Labor Demography

(c) Copyright is held by the authors.

Working papers of the Max Planck Institute for Demographic Research receive only limited review. Views or opinions expressed in working papers are attributable to the authors and do not necessarily reflect those of the Institute. 


\title{
Mobile Phone Network and Migration: Evidence from Myanmar*
}

\author{
Riccardo Ciacci $^{\dagger}$ \\ Jorge García-Hombrados \\ Ayesha Zainudeen ${ }^{\S}$ \\ May 4, 2020
}

\begin{abstract}
This study explores the effect of the expansion of mobile phone signal on migration decisions in Myanmar. The empirical strategy proposed follows Manacorda and Tesei (2019) and Andersen et al. (2011), it uses variation in lightning frequency across space as an instrumental variable for the expansion of mobile phone signal. Our results suggest that longer exposure to mobile phone network decreases migration. Specifically, an increase of 1 s.d. in the time exposed to mobile phone signal diminishes the probability of household members to migrate by $17 \%$. We find empirical evidence suggesting that such findings are driven by the positive effects of access to mobile phone signal on labor market outcomes and on perceived well-being.
\end{abstract}

Keywords: mobile phones, migration, labor market outcomes.

JEL codes: F22, O53, L96

*This work was carried out with the aid of a grant from the International Development Research Centre (IDRC), Canada and the Department for International Development (DFID), UK. This project was also partially funded by the ERC-StG COSTPOST (\#336475) to Mikko Myrskylä

${ }^{\dagger}$ Universidad Pontificia Comillas, Department of Business Management (email: rciacci@comillas.edu).

‡García-Hombrados: Corresponding author. Max Planck Institute for Demographic Research (MPIDR) and Universidad Autónoma de Madrid (email: jorge.garciah@uam.es).

§LIRNEasia (email: ayesha@lirneasia.net). 


\section{Introduction}

This paper studies the effect of mobile phone coverage development on migration. It makes use of a novel instrumental variable approach suggested by Manacorda and Tesei (2019) and Andersen et al. (2011). We find that longer exposure to mobile phone network decreases migration. In a context where $11 \%$ of households include at least 1 migrant, an increase of 1 month in the time exposed to mobile phone decreases the probability of having a migrant in the household by 0.0024 percentage points. Furthermore, this paper explores the channels that might be driving this effect. It finds suggestive evidence that mobile phones enhances labor market opportunities, and in particular the probability of receiving a wage, by improving communication, social relationships and perceived wellbeing. Consequently, the opportunity cost of migration increases and both internal and international migration diminish.

The potential socioeconomic effects of the expansion and improvement of mobile phone signal in Myanmar are manifold. ${ }^{1}$ Different studies show evidence that particularly in developing countries with largely imperfect markets and high transport costs, the expansion of mobile phone coverage can improve different development outcomes (Aker, 2008; Jensen, 2007; Roller and Waverman, 1996; Andersen et al., 2012; Klonner and Nolen, 2010; Hall et al., 2014) and may facilitate institutional change (Shapiro and Weidmann, 2015; Aker et al., 2017; Andersen et al., 2011; Manacorda and Tesei, 2019). For example, Klonner and Nolen (2010) find that the roll out of mobile phone network in rural areas of South Africa increases the employment rate by 15 percentage points, with even larger effects for women; and Jensen (2007) and Aker (2008) show that the roll out of mobile phone signal leads to substantial welfare improvements for both producers and consumers in fishing areas of India and rural areas of Niger.

Less clear is however the link between the expansion of mobile phone network and migration. In principle, access to mobile phone signal may decrease the costs of migration through facilitating communication between the migrant and the family (migrating effect). However, the benefits of access to mobile phones in terms of labour market and access to information may also increase the opportunity cost of migration (non-migrating effect). Thus, the effect of expanding access to mobile phones on migration is theoretically ambiguous and remains an empirical question.

To the best of our knowledge, this question has been empirically explored in two previous studies, both of them suggesting that the roll out of mobile phone coverage could foster migration. Muto (2009) finds that mobile phones strengthen ethnic networks and enhances decisions to migrate to find a job. Aker et al. (2011) uses a randomised controlled trial design to evaluate the impact of an adult educational programme that teach students how to use simple mobile phones in Niger. They find that access to mobile phones in-

\footnotetext{
${ }^{1}$ Appendix Section A briefly describes the economic and political background in Myanmar .
} 
creases the likelihood of migration of at least one household member by 7 percentage points. In contrary, our paper shows that, in Myanmar, the roll-out of mobile phone network decreased migration suggesting that the causal link between mobile phones and migration might be context-dependent.

The document is structured as follows. Section 2 describes the recent process of expansion of mobile phone coverage in Myanmar. Then, section 3 introduces the empirical framework for the analysis and section 4 describes the data used in the analysis. Section 5 presents the main results of the study and section 6 concludes.

\section{The Expansion of Mobile Phone Signal across Myanmar}

Until January 2014 there was only one mobile phone operator in Myanmar: the stateled company Myanmar Post and Telecommunications (hereafter, MPT). Although MPT has been providing mobile phone services since the 90's in Myanmar, World Bank (2015) suggests that most rural and conflict areas across the country did not receive any mobile phone network and the signal provided was very poor in most areas until 2014. FINMARK (2013) estimates that only around $42 \%$ of the households in Myanmar were using mobile phones in 2013.

With the intention of increasing the deployment of telecommunication infrastructure and improving the access, efficiency and effectiveness of telecommunications services delivered in Myanmar to end users, the Government of Myanmar passed a new telecommunication law in October 2013. Such a law broke the MPT monopoly by allowing international and domestic private sector companies to participate in free and fair competition in the provision of telecommunication services including mobile phone services. The telecommunication law was followed by additional regulation developed by the Posts and Telecommunications Department of the Ministry of Communication in Myanmar. This regulation settles the details of licensing, spectrum, numbering, interconnection and access and competition in the telecommunication sector in Myanmar. Following the approval of the law, the international mobile phone operators Telenor and Ooredoo obtained licenses to provide telecommunication services in Myanmar as integrated license operators in January 2014. The new mobile phone operators were enabled to develop telecommunication infrastructure and provide network service (2G, 3G and $4 \mathrm{G})$. The new licensees committed to roll out mobile phone signal covering the $90 \%$ of Myanmar's territory in a period of five years.

The survey used in this paper was implemented in 420 villages and wards across Myanmar commissioned by LIRNEasia and conducted between February and March 2015. Information on the availability of mobile phone signal in a village or ward, and if so, on the date in which the signal was first established was collected at the village/ward 
level from a community leader. In 324 out of the 420 villages/wards surveyed, the community leader was interviewed and reported data on the timing and availability of mobile phone signal in his community.

Remarkably, by the time the survey was implemented in February-March 2015 only 27 community leaders reported that their village or ward did not receive any mobile phone signal. The map in figure 1 shows the timing of mobile phone installation in the villages and wards surveyed. Mainly led by MPT, the data reveal that although an important expansion of mobile phone network occurred in 2014 and early 2015, more than 50\% of the communities surveyed were already receiving mobile phone signal before 2014 when the new regulation started operating.

\section{Methodology}

This section introduces the empirical strategy for assessing the causal effects of length of exposure to mobile phone signal on migration. The main challenge in estimating the effects in this case is addressing the endogeneity in the link between these two variables. An endogeneity problem would arise if, for example, mobile phone coverage development positively correlates with unobservables that affect migration. We address this concern using an instrumental variable (hereafter, IV) approach.

Namely, we instrument mobile phone coverage development with flash activity. Figure 2 shows the incidence of lightnings across Myanmar using satellite geocoded information on lightning strikes. Figure 3 shows the distribution of such a variable. As these two figures show, there is substantial variation in the values this variable takes and across villages of Myanmar. This considerable variation is used to instrument the expansion of mobile phone signal in Myanmar.

Variation in lightning strikes has been previously used in the literature as an instrumental variable to predict the expansion of mobile phone (Manacorda and Tesei, 2019; Andersen et al., 2011, 2012). These studies contend that lightning strikes hinder the expansion of mobile phones. Specifically, they argue that lightning produces electrostatic discharges that damage mobile phone infrastructure and connectivity, increasing the cost of mobile phone signal provision. In the process of expansion of the mobile phone coverage, companies and governments provide network to areas with a lower incidence of lightning strikes in the first place, and then expand to areas with higher costs of provision. Furthermore, they also argue that conditional on climatic and geographical factors such as temperature, precipitation or altitude, lightning frequency should not affect socioeconomic outcomes other than through affecting the diffusion of telecommunication technologies.

In line with this argument, Andersen et al. (2012) shows that the frequency of light- 
ning did not affect growth before the expansion of the telecommunication technologies in the US and Manacorda and Tesei (2019) finds that before the arrival of mobile phone technology in Africa the frequency of lightning did not affect the number of protests. ${ }^{2}$ However, lightning frequency might also be correlated with other variables that affect socioeconomic outcomes such as precipitation, altitude and temperature. Therefore, these climatic factors that correlate with the frequency of lightning would need to be taken into account in the analysis to avoid the violation of the exclusion restriction.

Specifically, we consider the following regression models:

$$
\begin{gathered}
T_{i}=\alpha_{0}+\alpha_{1} Z_{i}+\alpha_{2} X_{i}++r_{i}+\alpha_{3} H_{i}+\mu_{i} \\
M_{i}=\delta_{0}+\delta_{1} \widehat{T}_{i}+\delta_{2} X_{i}+r_{i}+\delta_{3} H_{i}+u_{i}
\end{gathered}
$$

where equation (3.1) is the first stage regression and equation (3.2) is the second stage. $T$ is the length in months of exposure to mobile phone signal in the village/ward where household $i$ lives, $Z$ is the average yearly frequency of lightning between 2011-2014 in the village/ward where household $i$ lives, $X$ is a vector of climatic and geographical controls, $r$ is a fixed effect for households in rural villages and $H$ is a set of variables at the household and, in particular, at the household reference person (hereafter, HRP) level. ${ }^{3}$ Since the instrumental variable varies at ward/village level, standard errors are clustered at this level.

\section{Data}

The main source of information used in the analysis is a household level survey conducted in Myanmar in February-March 2015 that was commissioned by LIRNEasia. The survey collected detailed information from 8138 households and was representative for 14 out of the 17 regions and for $97 \%$ of Myanmar's households. The population for which the household survey was not representative includes the 3\% of Myanmar's households that live in the 32 townships that are currently under a situation of conflict. The household survey includes information on sociodemographic characteristics, dwelling characteristics, household assets and whether there is any migrant in the family. Furthermore, the questionnaire includes an individual module that was applied to a randomly chosen member of the household. ${ }^{4}$ This individual module collects information on labour participation, ICT use, information access, respondent lifestyle and perceived impacts of

\footnotetext{
${ }^{2}$ Section 5.4 provides evidence in our setting.

${ }^{3}$ This set of variables is comprised of two variables: sex of the HRP and her/his age.

${ }^{4}$ The selection of the household member interviewed for the individual module was conducted through a Kish Grid among those members between 15 and 65 years old.
} 
ICT.

The primary sampling unit for the household survey was the village/ward. In total, households from 420 wards or villages were interviewed. In each ward or village, in addition to the households in the sample, a community leader was interviewed for the collection of village/ward level data. The village/ward level survey includes information on socioeconomic status, demography, ICT availability, infrastructure, natural environment and connection in the ward/village. For those places with mobile phone signal, the questionnaire also requests information on when was mobile phone signal first available. In total, information on whether mobile phone signal was available and the date of installation was collected for 324 wards, including 27 wards or villages without any signal. We use this information on the month and year where the signal was provided in a village to construct our treatment variable, which measures the number of months of exposure to mobile phone signal by the time of the survey. This variable only varies at the village level.

A key element of the analysis is the use of climatic and geographic information on precipitation, temperature, lightning and altitude as control variables. The precipitation and temperature data for the period 2011-2014 is obtained from the CRU TS v.3.23 database. ${ }^{5}$ The latter is a high-resolution World dataset that reports monthly information on precipitation, temperature, wet-day frequency, sunshine duration, relative humidity, wind and ground frost at a geographical grid level of $0.5^{\circ} \times 0.5^{\circ}$ resolution for the period 1901-2014 The data is publicly available through the Climatic Research Unit at the University of East Anglia and it is based on information reported by weather stations worldwide.

The lightning frequency data for the period 2011-2014 is obtained from the Lightning Imaging Sensor Very High Climatology dataset. ${ }^{6}$ This satellite-based dataset reports the date and the geographic coordinates for every lightning detected worldwide by the NASA Lightning Imaging Sensor for the period January 1998-April 2015. The altitude data is extracted from the SRTM3 dataset provided by the NASA. This dataset provides World altitude data with 90-meter resolution.

The main analysis will be conducted using the sample of 6,021 households living in the 324 villages/wards for which we have information on length of exposure to mobile phone signal. Descriptive statistics for the households in this sample are reported in table 1. The data reveal that there is a mobile phone in $62 \%$ of these households and nearly $96 \%$ of the households live in a village with access to mobile phone signal. The average household size is 4 members. $11 \%$ of such households have at least a migrant among their family members. Migration in the households included in the analytical sample occurs mainly within the country.

${ }^{5}$ The data are available at: https://crudata.uea.ac.uk/cru/data/hrg/cru_ts_3.23/

${ }^{6}$ This database is available at: http://thunder. nsstc . nasa.gov/lisib/lissearch.pl? coords=?551, 37 


\section{Results}

\subsection{First stage}

Panel A of Table 2 shows results of the first stage regression. Column (1) reports the results omitting both the rural fixed effects and the HRP controls. The instrument is statistically negative at standard levels with an F-statistic equal to 17.58. Columns (2) and (3) respectively add the rural fixed effects and the HRP controls. Results do not change: both the estimated coefficient and F-statistic are stable across regressions.

Column (3) shows the results of our preferred specification. Such results suggest that larger flash activity substantially reduces mobile phone coverage development. Namely, an increase of 1 s.d. in the flash activity drags out mobile phone coverage development about 16 months.

Figure 4 displays a binned scatter plot of $T$ and $Z$ partialling out the control variables of equation (3.1). In line with the first stage results, the two variables are negatively correlated. The higher the flash activity around a village, the later mobile phone coverage was delivered and thus, the shorter the length of exposure to mobile phone network.

One potential concern would be that results could be driven by extreme values of lightning activity. To rule out this possibility, Panel B of Table 2 shows the estimates of the first stage regression using the instrument in logs. Results are robust to such a change: the instrument has a statistical negative effect on the endogenous regressor. Nonetheless, there might concerns that in this case the instrument is weak since the F-statistic across columns (1), (2) and (3) ranges from 9.84 to 10.77. We will address this concern in the results of the second stage.

\subsection{Second stage}

Table 3 shows the estimates of the second stage regression. Panel A instruments $T$ with $Z$, while Panel B instruments $T$ with $\log (Z)$. Column (1) omits the rural fixed effects and HRP controls, columns (2) adds the former and column (3) the latter.

Column (3) of Panel A is our main second stage specification. Results of this specification are negative and statistically different from zero, they suggest that mobile phone coverage reduces migration. Specifically, receiving mobile phone network one month in advance reduces the probability of migration in the household by 0.0024 percentage points. Put it differently, an increase of 1 s.d. in the endogenous variable decreases the probability of household members to migrate by $17 \%$.

Panel B shows that results are not driven by extreme values of flash activities: using $Z$, in logs as instrument does not affect our findings. Indeed, estimated coefficients of columns (1)-(3) of Panel B are similar in point estimate to their counterparts in Table A and 
statistically negative at standard levels. Since for this specification there were concerns that the instrument was weak, this table reports the results of the $\mathrm{p}$ value associated to the Conditional Likelihood Ratio test (Moreira, 2003; Andrews et al., 2006, 2007).This p-value equals 0 across columns (1)-(3), ruling out the possibility that results are driven by a weak instrument problem.

\subsection{Reduced form}

This section presents the results of running the reduced form regression model of our analysis. We consider the following equation:

$$
M_{i}=\beta_{0}+\beta_{1} Z_{i}+\beta_{2} X_{i}+r_{i}+\beta_{3} H_{i}+\eta_{i}
$$

Panel A of Table 4 shows the resultss of estimating equation (5.1). displays the results of running equation (5.1). Column (1) omits the rural dummy and HRP controls, whereas columns (2) adds the former and column (3) the latter. Results are stable across specifications: flash activity is positively correlated with migration. Yet, the effect is not economically meaningful. In particular, an increase of 1 s.d. in $Z$ increases the probability of a household member to migrate by $3.4 \%$.

Panel B of Table 4 shows the results or running equation (5.1) using the $Z$ in logs. Results are similar to Panel A. They suggest that lightning activity has a positive effect on migration.

\subsection{Exclusion restriction}

There might be concerns on the exclusion restriction of our IV estimation. In this setting, the exclusion restriction assumption is that lightning activity affects migration only through mobile phone coverage. This assumption is untestable, yet we can provide some empirical evidence to explore its plausibility.

According to the exclusion restriction assumption the reduced form effect of flash activity on migration should take place in villages where there is mobile phone coverage. Put it differently, if flash activity affects migration only via mobile phone coverage, it makes sense to think that in villages where there is no mobile phone coverage the former has no effect on the latter.

Tables 5 and 6 respectively report the results of running equation (5.1) for villages without and with mobile phone coverage. Coherently with the exclusion restriction: flash activity does not affect migration in villages without mobile phone signal. No estimated coefficient is statistically different from zero in Table 5 . Furthermore, the $95 \%$ confidence interval of the estimate of our main specification (column (3), Panel A) suggests that the 
effect of lightning activity on migration, rounded to the second decimal, in villages without mobile signal is at most 0 .

Nonetheless, there might be concerns that these results are driven by the fewer number of observations of Table 5 with respect to Table 6 . To eplore this hypothesis Figure 5 presents the results of running equation (5.1) dividing the sample in tertiles according to the length of exposure to mobile phone network $T$. According to the exclusion restriction hypothesis the effect of flash activity on migration should be larger where the length of exposure to mobile phone network is higher. Thus, we should observe a positive trend in Figure 5 .

Results support the exclusion restriction. Figure 6 presents the same analysis using $\mathrm{Z}$ in logs. Also in this case the plot exhibits a positive trend in line with the exclusion restriction.

\subsection{OLS}

This section presents the results of running the structural equation and compares such OLS estimates to the IV estimates. Namely, we consider the following structural relation:

$$
M_{i}=\gamma_{0}+\gamma_{1} T_{i}+\gamma_{2} X_{i}+r_{i}+\gamma_{3} H_{i}+\epsilon_{i}
$$

Table 7 shows the results of running equation (5.2). As in previous tables, column (1) omits the rural fixed effects and HRP controls, columns (2) adds the former and column (3) the latter. In every regression, our estimated coefficient of interest is statistically negative, but smaller in absolute value, than our IV estimate. This suggests that the correlation between unobervables and $T$ has the same sign as the correlation between unobervables and $M$, this would bias upwards our OLS estimates. Another explanation for larger coefficients in the IV regression is the existence of measurement error in the variables that report the month and year in which the mobile phone coverage was provided in the villages. This measurement error problem would be overcome by the IV approach.

Following the methodology developed in Oster (2017) and Ciacci and Rascón (2019) we can compute a measure of the selection on unobservables proportional to selection on controls needed to yield our IV estimates. We suspect that:

- Unobservables are positively correlated with $M$, given the difference between IV and OLS estimates has negative sign and the plausible positive relation between unobservables and $T$.

- $T$ is negatively correlated with control variables, given results from the first-stage regression (a complete table is available upon request). 
Hence, it makes sense to think that the coefficient of proportionality $\delta$ is positive. This is exactly the case: table 7 reports the exact value of $\delta$, for both $Z$ in levels and logs, in each column of the table. In our main specification we see that $\delta$ ranges from 0.21 , when $Z$ is in levels, to 0.28 when $Z$ is in logs. Such low values of $\delta$ give further support to the validity of our IV estimates.

\subsection{Channels}

This section explores the potential mechanisms through which the expansion of mobile phone affected migration in Myanmar. In principle, there are two opposed channels potentially at play. On the one hand, access to mobile phone signal might decrease the costs of migration, we refer to this channel as the migrating effect. For example, access to mobile phones might help the migrant to gather information about migration. On the other hand, the benefits of access to mobile phones in terms of labour market and access to information may also increase the opportunity cost of migration, we refer to this channel as the non-migrating effect. For example, mobile phones might help the migrant to gather information about the labor market and bargain better standards.

Results in tables 3 and 7 suggest that in our setting the non-migrating effect dominates the migrating effect. To investigate the mechanisms and better understand whether mobile phones affect differently internal and international migration, we run equation (3.2) for different outcomes: having a migrant in the household who migrated inside Myanmar, having a migrant in the household who migrated abroad, binary variable taking value 1 if the individual received a wage and perceptions on knowledge, social relationships and happiness. These last four variables are drawn from the individual module of the survey. This module collects information about one person per household randomly chosen among all adult household members.

Results of this analysis are reported in table 8. As previously Panel A reports results for $Z$ in levels, whereas Panel B reports results for $Z$ in logs. Columns (1) and (2) respectively show results for internal and international migration. Coherent with the nonmigrating effect mobile phones reduced both sorts of migrations. Specifically, an increase of 1 s.d. in the endogenous variable diminishes the probability of household members to migrate internally by $11 \%$ and abroad by $8 \%$. These findings are stable also when using $Z$ in logs.

Next, we explore the impact of mobile phone coverage development on wages. Results are aligned with the non-migrating effect: an increase of 1 s.d. in the endogenous variable enhances the probability of receiving a wage by $8.5 \%$. Results hold also in Panel $B$ of the same table.

With this evidence at hand, we turn to perception variables. It might be argued that mobile phones increase the opportunity cost of migration by helping individuals to gather 
more information and be connected. In line with this hypothesis, the descriptive statistics reported in table 9 reveal that the vast majority of individuals (ranging from $69 \%$ to $81 \%$ ) perceived that mobile phones helped them to increase their economic status, knowledge, social relationships and emotional wellbeing. Furthermore, columns (4), (5) and (6) in table 8 investigate the effect of length of exposure to mobile phones on these outcomes. The estimates suggest that not only individuals perceived that mobile phones improved their knowledge, skills and wellbeing but also that this effect grows with time exposed to mobile phones. These results are coherent with Aker and Mbiti (2010).

\section{Conclusions}

In this paper, we study the effect of expanding mobile phone coverage on migration in Myanmar. Using a novel IV approach led by a recent line of the literature (see, inter alia, Manacorda and Tesei (2019), Andersen et al. (2011) and Andersen et al. (2012)), we find that longer exposure to mobile phone coverage reduces migration. Moreover, our empirical analysis suggests that this effect takes place since mobile phones improve labour market outcomes and perceived well being. Our analysis also suggests that the instrument is not weak and the exclusion restriction is plausible in our setting.

This paper has two main contributions. First, to the best of our knowledge, it is one of the first papers to study the effect of mobile phone coverage development on migration and the mechanisms driving this effect. Second, the results of this study are different from previous ones conducted in African countries. These results highlight that the effect of expanding mobile phones on migration are context-dependent and call for more research on the factors that explain these differential effects. 


\section{Figures}

Figure 1: Expansion of mobile phone signal across the villages sampled

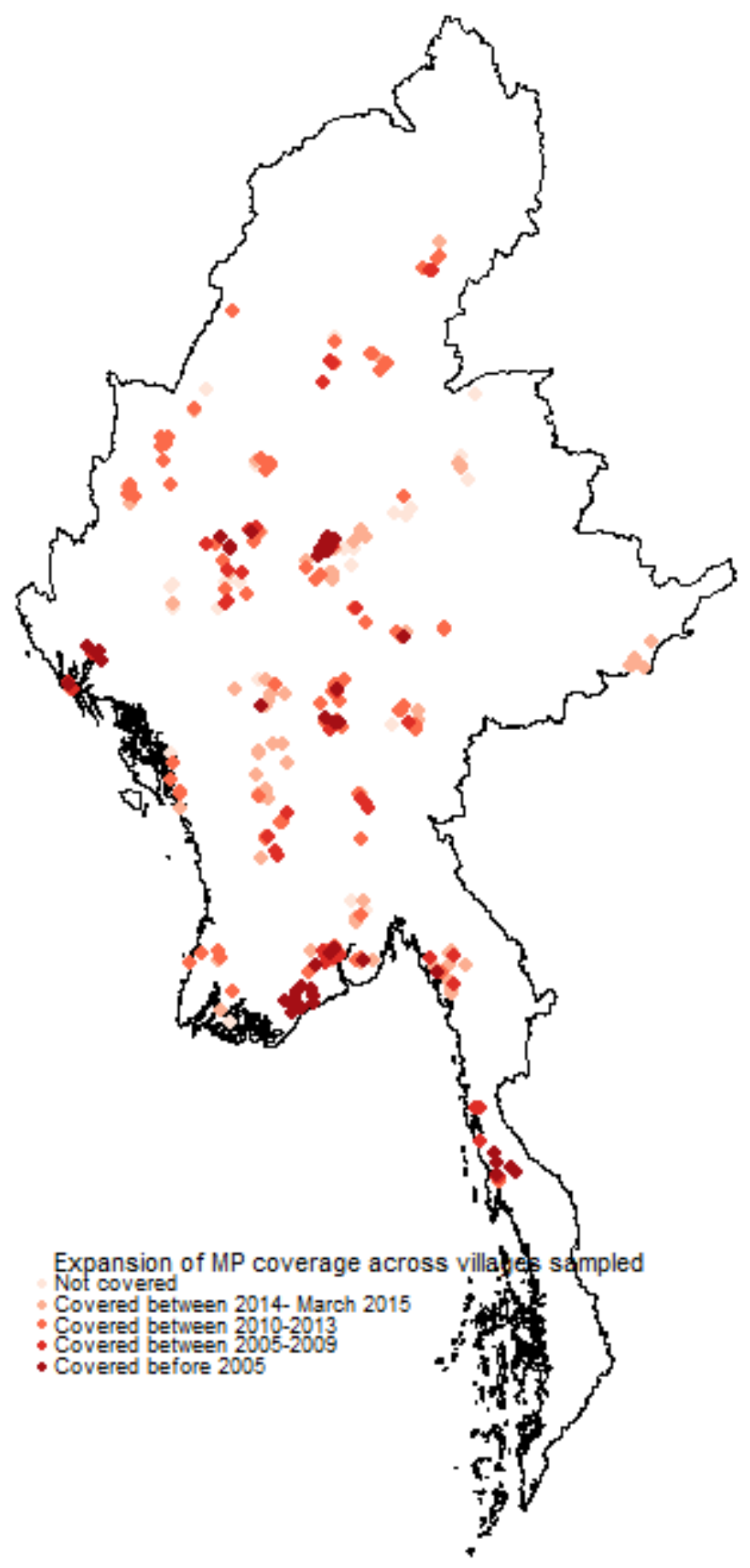


Figure 2: Incidence of lightnings across Myanmar (2010-2014)

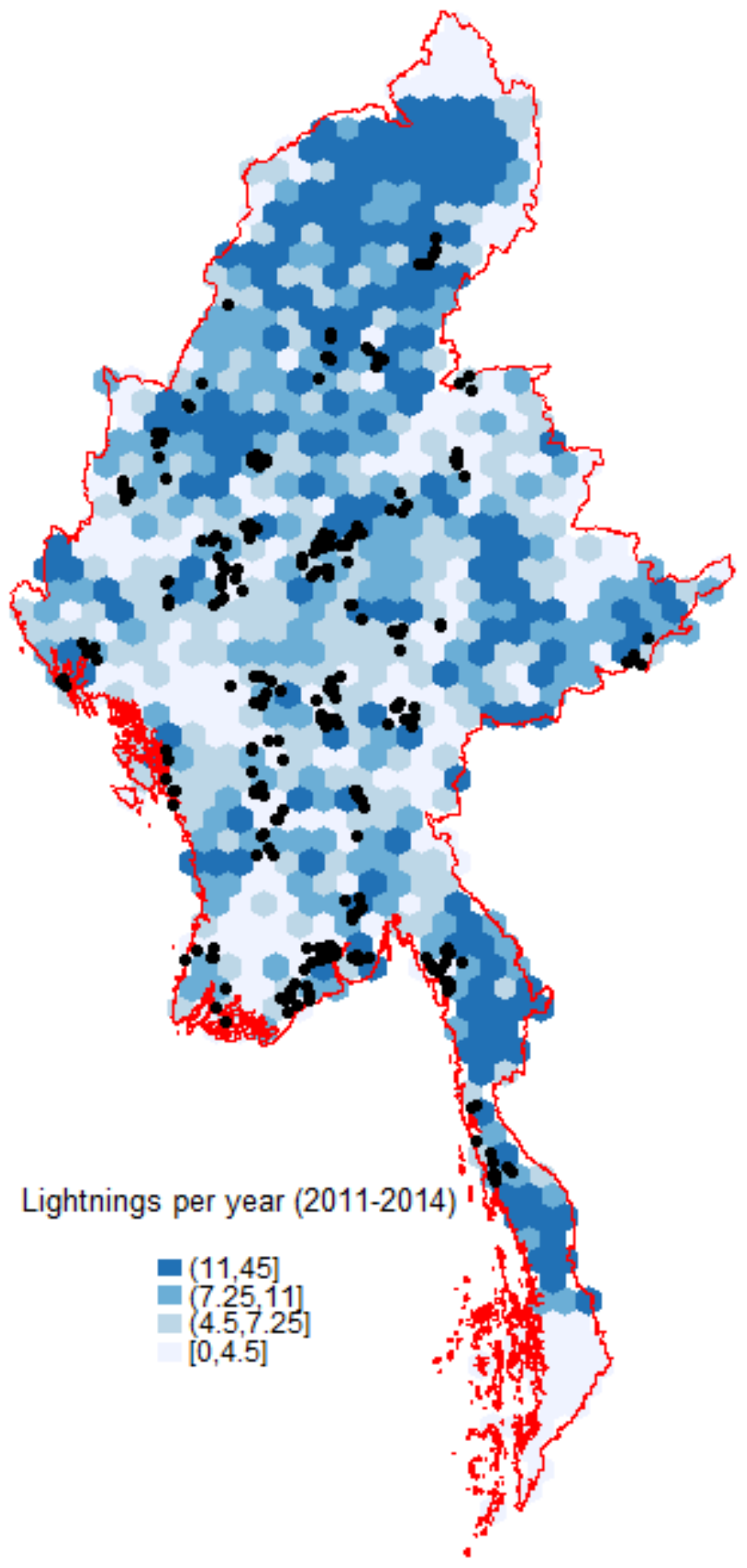


Figure 3: Distribution of $Z$.

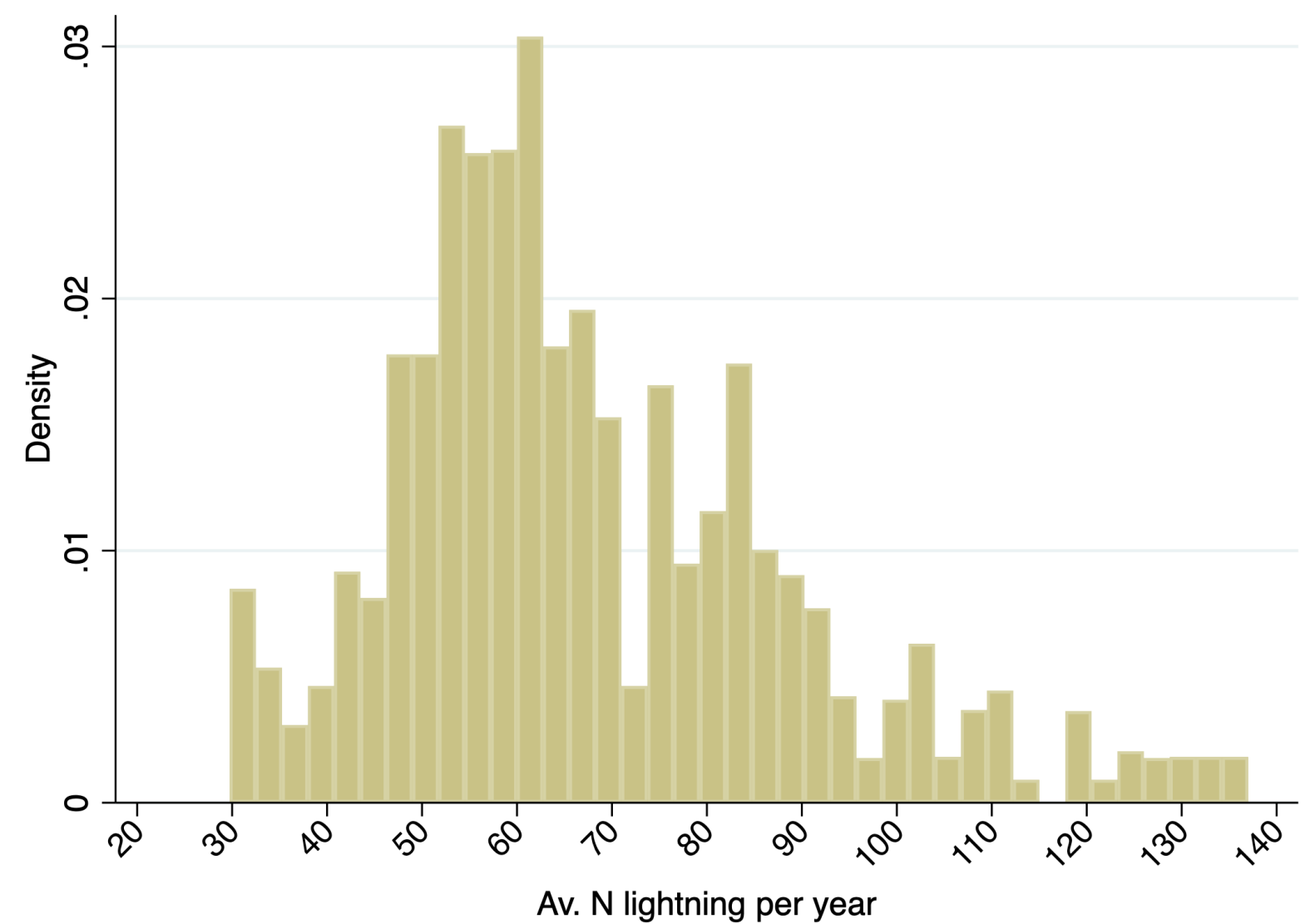

Notes: Histogram of $Z$. 
Figure 4: First stage relation

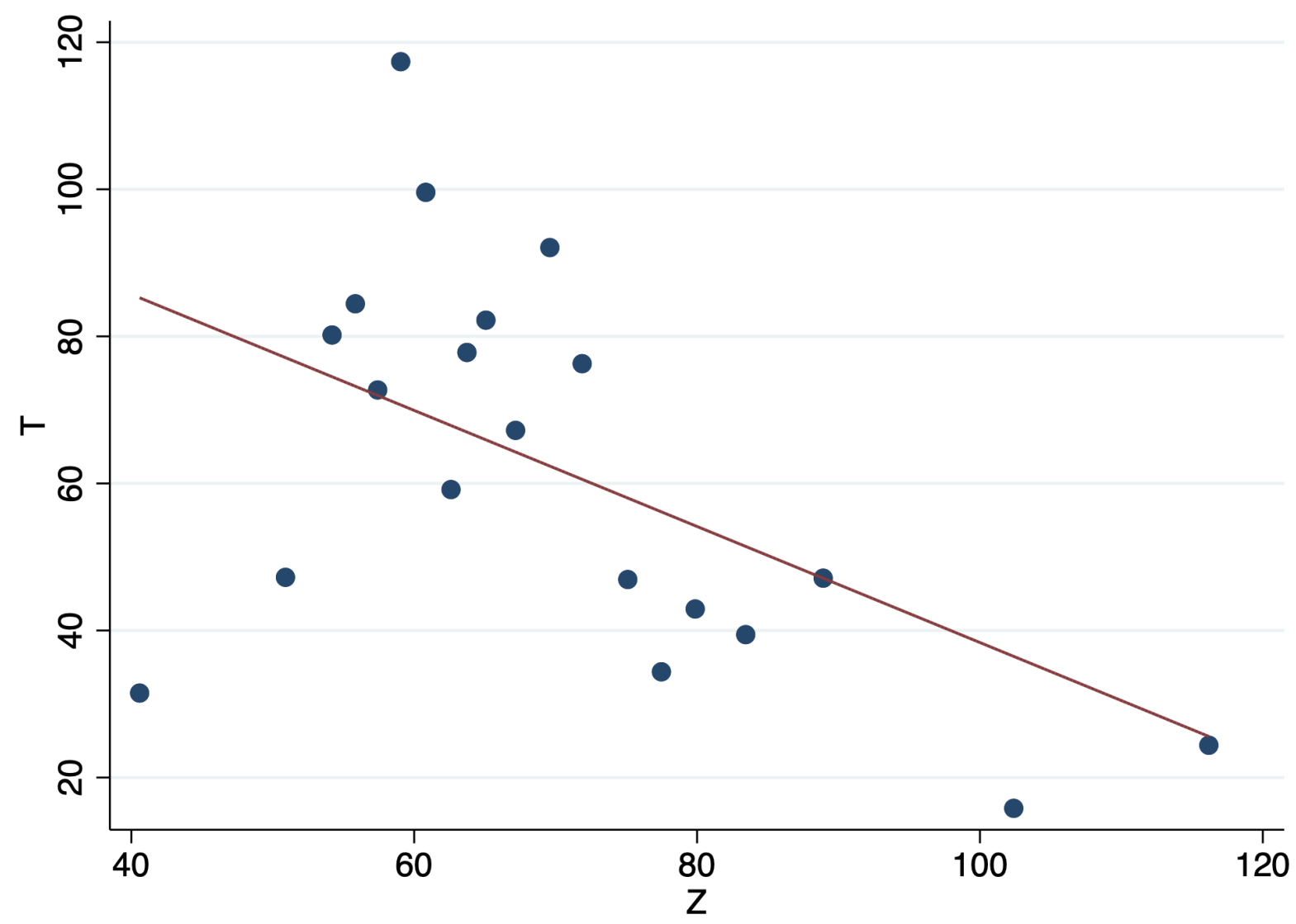

Notes: This figure displays a binned scatter plot of $T$ and $Z$ partialling out the control variables of equation (3.1). The two variables are negatively correlated in line with the first stage results. 
Figure 5: Reduced form: concerns on exclusion restriction

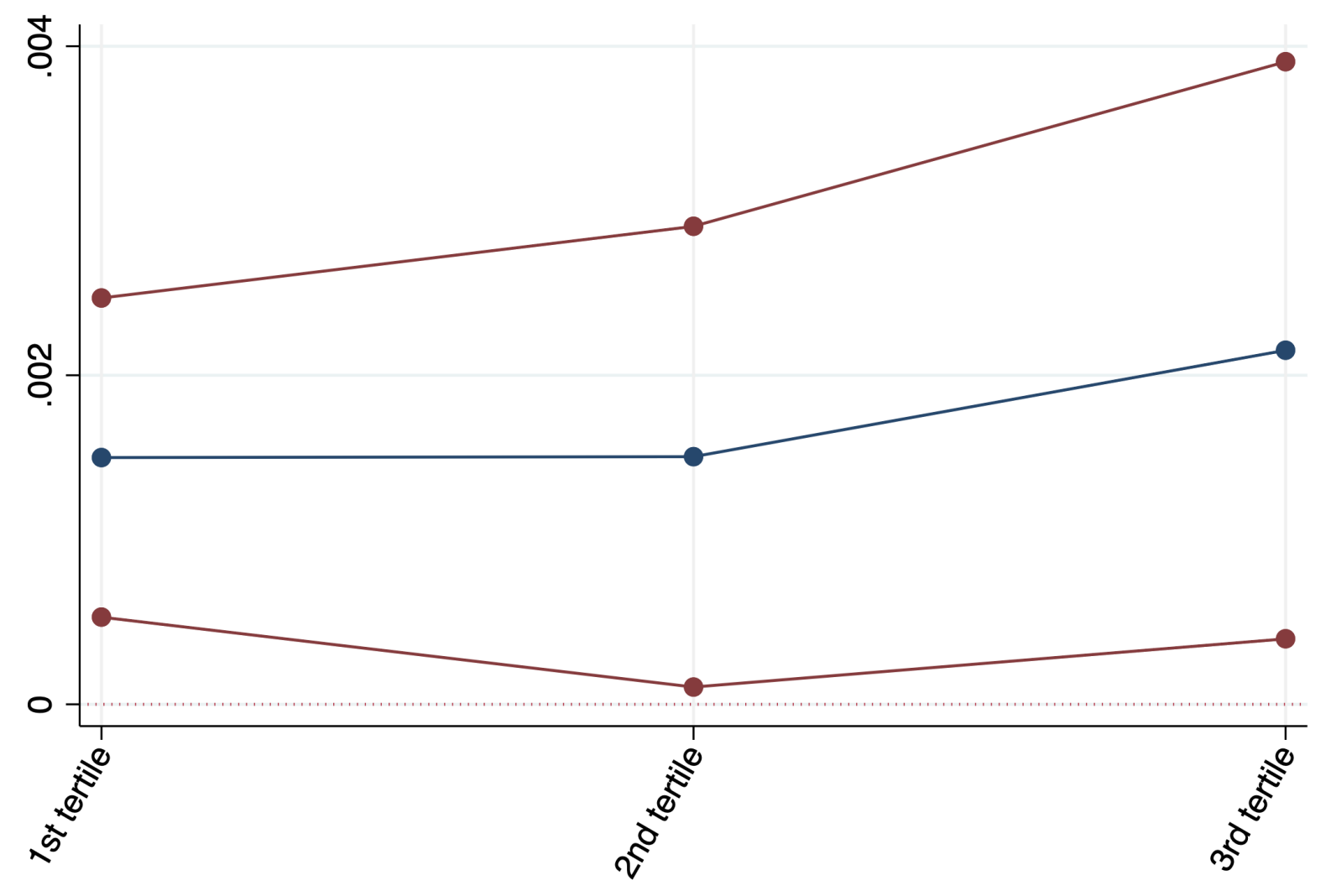

Reduced form by tertiles of time signal, $95 \% \mathrm{Cl}$

Notes: This figure displays the estimated coefficients, and its $95 \%$ confidence intervals, of running equation (5.1) for each of the three tertiles of $T$. If flash activity affects migration only through mobile phone coverage the effect should be larger where $T$ is larger. Hence, we should observe a positive trend in this figure. 
Figure 6: Reduced form: concerns on exclusion restriction

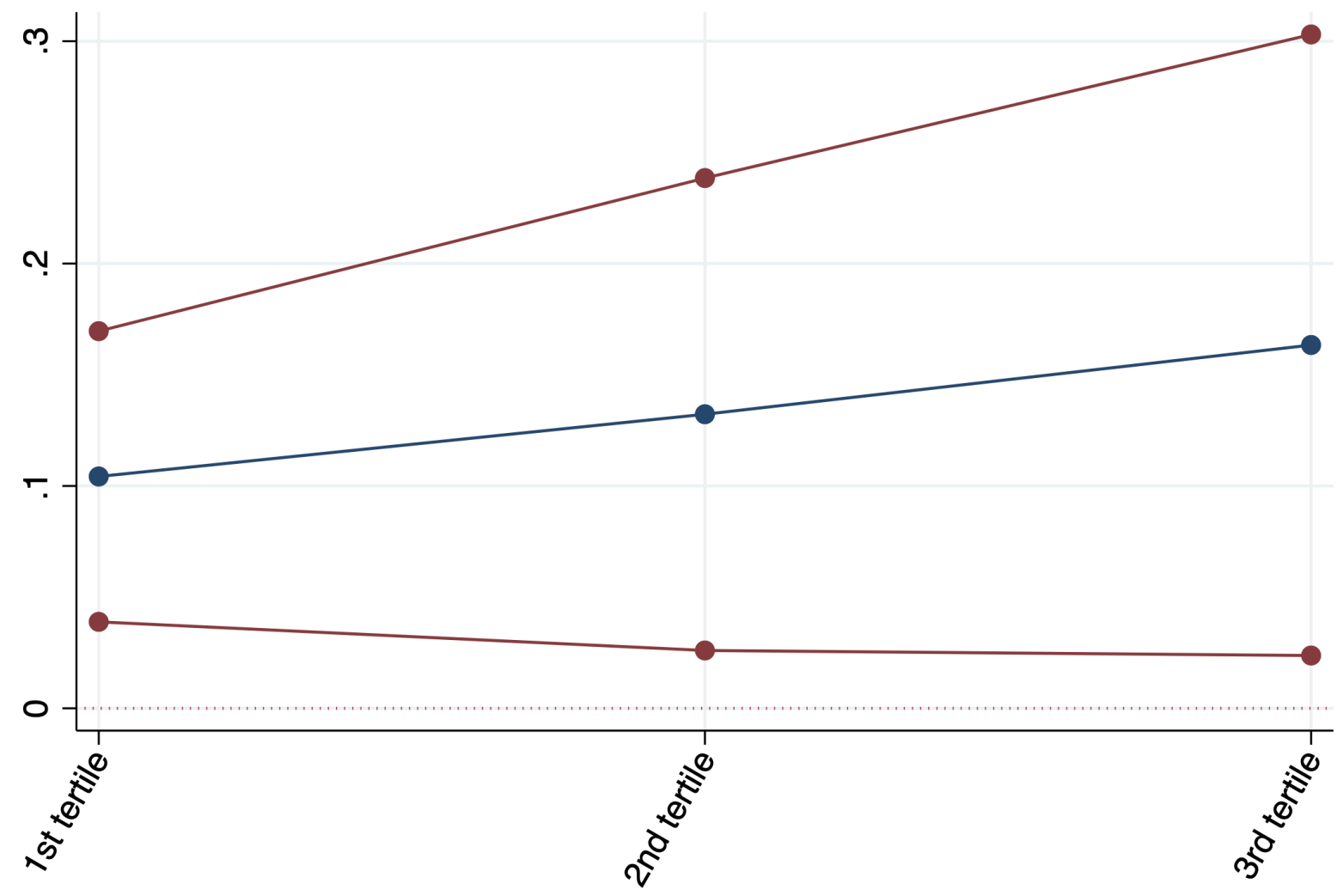

Reduced form by tertiles of time signal, $95 \% \mathrm{Cl}$

Notes: This figure displays the estimated coefficients, and its $95 \%$ confidence intervals, of running equation (5.1), with $Z$ in logs, for each of the three tertiles of $T$. If flash activity affects migration only through mobile phone coverage the effect should be larger where $T$ is larger. Hence, we should observe a positive trend in this figure. 


\section{Tables}

Table 1: Descriptive statistics

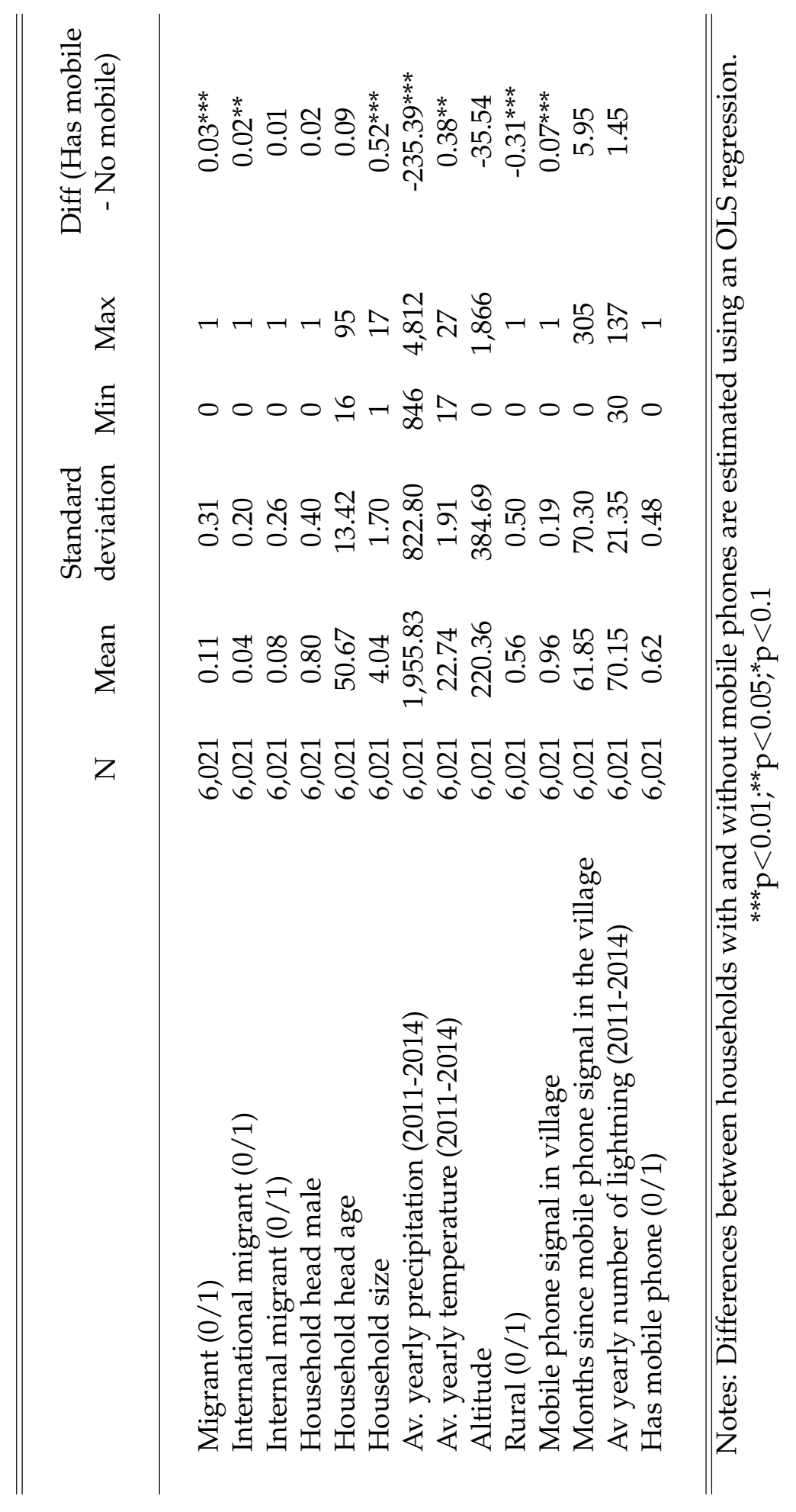


Table 2: First stage

\begin{tabular}{|c|c|c|c|}
\hline & $\begin{array}{l}(1) \\
T\end{array}$ & $\begin{array}{l}(2) \\
T\end{array}$ & $\begin{array}{l}\text { (3) } \\
T\end{array}$ \\
\hline \multicolumn{4}{|l|}{ Panel A } \\
\hline Z & $\begin{array}{c}-0.789^{* * *} \\
(0.188)\end{array}$ & $\begin{array}{c}-0.752^{* * *} \\
(0.188)\end{array}$ & $\begin{array}{c}-0.759^{* * *} \\
(0.189)\end{array}$ \\
\hline F-statistic & 17.58 & 15.93 & 16.10 \\
\hline \multicolumn{4}{|l|}{ Panel B } \\
\hline $\log (Z)$ & $\begin{array}{c}-45.53^{* * *} \\
(13.87)\end{array}$ & $\begin{array}{c}-43.28^{* * *} \\
(13.88)\end{array}$ & $\begin{array}{c}-43.68^{* * *} \\
(13.92)\end{array}$ \\
\hline F-statistic & 10.77 & 9.722 & 9.842 \\
\hline Observations & 6,138 & 6,138 & 6,021 \\
\hline Clustered variance at village level & Y & Y & Y \\
\hline Climate controls & Y & $\mathrm{Y}$ & $\mathrm{Y}$ \\
\hline Rural FE & $\mathrm{N}$ & $\mathrm{Y}$ & $\mathrm{Y}$ \\
\hline HRP controls & $\mathrm{N}$ & $\mathrm{N}$ & $\mathrm{Y}$ \\
\hline
\end{tabular}

Robust standard errors in parentheses

*** $\mathrm{p}<0.01,{ }^{* *} \mathrm{p}<0.05,{ }^{*} \mathrm{p}<0.1$

Notes: This table displays the estimated coefficients of running the firststage regression model, equation (3.1). Data is at household level. Standard errors are clustered at village/ward level. Column (1) omits the rural fixed effects and HRP controls, columns (2) adds the former and column (3) the latter. Results do not change: both the estimated coefficient and F-statistic are stable across regressions. 
Table 3: Second stage

\begin{tabular}{llll}
\hline \hline & $(1)$ & $(2)$ & $(3)$ \\
$M$ & $M$ & $M$ \\
\hline \hline
\end{tabular}

\section{Panel A}

\begin{tabular}{lccc}
\hline$T$ & $-0.00232^{* * *}$ & $-0.00241^{* * *}$ & $-0.00243^{* * *}$ \\
& $(0.000655)$ & $(0.000718)$ & $(0.000716)$
\end{tabular}

\begin{tabular}{|c|c|c|c|}
\hline \multicolumn{4}{|l|}{ Panel B } \\
\hline$T$ & $\begin{array}{c}-0.00298^{* * *} \\
(0.000960)\end{array}$ & $\begin{array}{c}-0.00311^{* * *} \\
(0.00106)\end{array}$ & $\begin{array}{c}-0.00308^{* * *} \\
(0.00103)\end{array}$ \\
\hline $\mathrm{p}$ value CLR & 0 & 0 & 0 \\
\hline Observations & 6,138 & 6,138 & 6,021 \\
\hline Clustered variance at village level & Y & Y & Y \\
\hline Climate controls & $\mathrm{Y}$ & Y & $\mathrm{Y}$ \\
\hline Rural FE & $\mathrm{N}$ & $\mathrm{Y}$ & $\mathrm{Y}$ \\
\hline HRP controls & $\mathrm{N}$ & $\mathrm{N}$ & $\mathrm{Y}$ \\
\hline
\end{tabular}

Robust standard errors in parentheses

$$
{ }^{* * *} \mathrm{p}<0.01,{ }^{* *} \mathrm{p}<0.05,{ }^{*} \mathrm{p}<0.1
$$

Notes: This table displays the estimated coefficients of running the second stage regression model, equation (3.2). Data is at household level. Standard errors are clustered at village/ward level. Column (1) omits the rural fixed effects and HRP controls, columns (2) adds the former and column (3) the latter. Results do not change: both the estimated coefficient and F-statistic are stable across regressions. Yet, the F-statistic ranges from 9.84 to 10.77. 
Table 4: Reduced form

\begin{tabular}{lccc}
\hline \hline & $(1)$ & $(2)$ & $(3)$ \\
& $M$ & $M$ & $M$ \\
\hline \hline & & & \\
Panel A & & & \\
\hline$Z$ & $0.00180^{* * *}$ & $0.00158^{* * *}$ & $0.00160^{* * *}$ \\
& $(0.000315)$ & $(0.000323)$ & $(0.000323)$
\end{tabular}

\begin{tabular}{llll}
\hline & & & \\
Panel B & $0.128^{* * *}$ & $0.113^{* * *}$ & $0.112^{* * *}$ \\
$\log (Z)$ & $(0.0198)$ & $(0.0215)$ & $(0.0216)$
\end{tabular}

\begin{tabular}{lccc} 
Observations & 6,138 & 6,138 & 6,021 \\
Clustered variance at village level & Y & Y & Y \\
Climate controls & Y & Y & Y \\
Rural FE & N & Y & Y \\
HRP controls & N & N & Y \\
\hline \hline
\end{tabular}

Robust standard errors in parentheses

${ }^{* * *} \mathrm{p}<0.01,{ }^{* *} \mathrm{p}<0.05,{ }^{*} \mathrm{p}<0.1$

Notes: This table displays the estimated coefficients of running the reduced form regression model, equation (5.1). Data is at household level. Standard errors are clustered at village/ward level. Column (1) omits the rural fixed effects and HRP controls, columns (2) adds the former and column (3) the latter. 
Table 5: Reduced form: concerns on exclusion restriction

\begin{tabular}{lccc}
\hline \hline & $(1)$ & $(2)$ & $(3)$ \\
& $M$ & $M$ & $M$ \\
\hline \hline & & & \\
Panel A & & & \\
\hline$Z$ & -0.000301 & -0.000339 & -0.000678 \\
& $(0.00182)$ & $(0.00187)$ & $(0.00182)$
\end{tabular}

\begin{tabular}{lccc} 
Panel B & & & \\
\hline $\log (Z)$ & -0.0288 & -0.0301 & -0.0494 \\
& $(0.114)$ & $(0.115)$ & $(0.112)$
\end{tabular}

\begin{tabular}{lccc}
\hline & & & \\
Observations & 235 & 235 & 230 \\
Clustered variance at village level & Y & Y & Y \\
Climate controls & Y & Y & Y \\
Rural FE & N & Y & Y \\
HRP controls & N & N & Y \\
\hline \hline
\end{tabular}

Robust standard errors in parentheses

${ }^{* * *} \mathrm{p}<0.01,{ }^{* *} \mathrm{p}<0.05,{ }^{*} \mathrm{p}<0.1$

Notes: This table displays the estimated coefficients of running the reduced form regression model, equation (5.1) for villages without mobile phone signal. Data is at household level. Standard errors are clustered at village/ward level. Column (1) omits the rural fixed effects and HRP controls, columns (2) adds the former and column (3) the latter. 
Table 6: Reduced form: concerns on exclusion restriction

\begin{tabular}{llll}
\hline \hline & $(1)$ & $(2)$ & $(3)$ \\
$M$ & $M$ & $M$ \\
\hline \hline
\end{tabular}

\section{Panel A}

\begin{tabular}{llll}
\hline $\mathrm{P}$ & $0.00176^{* * *}$ & $0.00174^{* * *}$ & $0.00178^{* * *}$ \\
& $(0.000337)$ & $(0.000332)$ & $(0.000333)$
\end{tabular}

\begin{tabular}{llll} 
Panel B & & & \\
\hline $\log (Z)$ & $0.126^{* * *}$ & $0.125^{* * *}$ & $0.126^{* * *}$ \\
& $(0.0228)$ & $(0.0226)$ & $(0.0227)$
\end{tabular}

\begin{tabular}{lccc} 
Observations & 7,016 & 7,016 & 6,891 \\
Clustered variance at village level & Y & Y & Y \\
Climate controls & Y & Y & Y \\
Rural FE & N & Y & Y \\
HRP controls & N & N & Y \\
\hline \hline
\end{tabular}

Robust standard errors in parentheses

${ }^{* * *} \mathrm{p}<0.01,{ }^{* *} \mathrm{p}<0.05,{ }^{*} \mathrm{p}<0.1$

Notes: This table displays the estimated coefficients of running the reduced form regression model, equation (5.1) for villages with mobile phone signal. Data is at household level. Standard errors are clustered at village/ward level. Column (1) omits the rural fixed effects and HRP controls, columns (2) adds the former and column (3) the latter. 
Table 7: OLS

\begin{tabular}{lccc}
\hline \hline VARIABLES & $(1)$ & $(2)$ & $(3)$ \\
$T$ & $M$ & $M$ & $M$ \\
\hline \hline & & & \\
& $-0.000419^{* * *}$ & $-0.000412^{* * *}$ & $-0.000418^{* * *}$ \\
& $(8.44 \mathrm{e}-05)$ & $(8.57 \mathrm{e}-05)$ & $(8.37 \mathrm{e}-05)$ \\
Observations & & & \\
Clustered variance at village level & 6,138 & 6,138 & 6,021 \\
Climate controls & $\mathrm{Y}$ & $\mathrm{Y}$ & $\mathrm{Y}$ \\
Rural FE & $\mathrm{Y}$ & $\mathrm{Y}$ & $\mathrm{Y}$ \\
HRP controls & $\mathrm{N}$ & $\mathrm{Y}$ & $\mathrm{Y}$ \\
$\delta$ & $\mathrm{N}$ & $\mathrm{N}$ & $\mathrm{Y}$ \\
$\delta$ logs & 0.15 & 0.15 & 0.21 \\
\hline \hline & 0.22 & 0.23 & 0.28 \\
\hline
\end{tabular}

Robust standard errors in parentheses

${ }^{* * *} \mathrm{p}<0.01,{ }^{* *} \mathrm{p}<0.05,{ }^{*} \mathrm{p}<0.1$

Notes: This table displays the estimated coefficients of running the structural regression model, equation (5.2). Data is at household level. Standard errors are clustered at village/ward level. Column (1) omits the rural fixed effects and HRP controls, columns (2) adds the former and column (3) the latter. 
Table 8: Channels

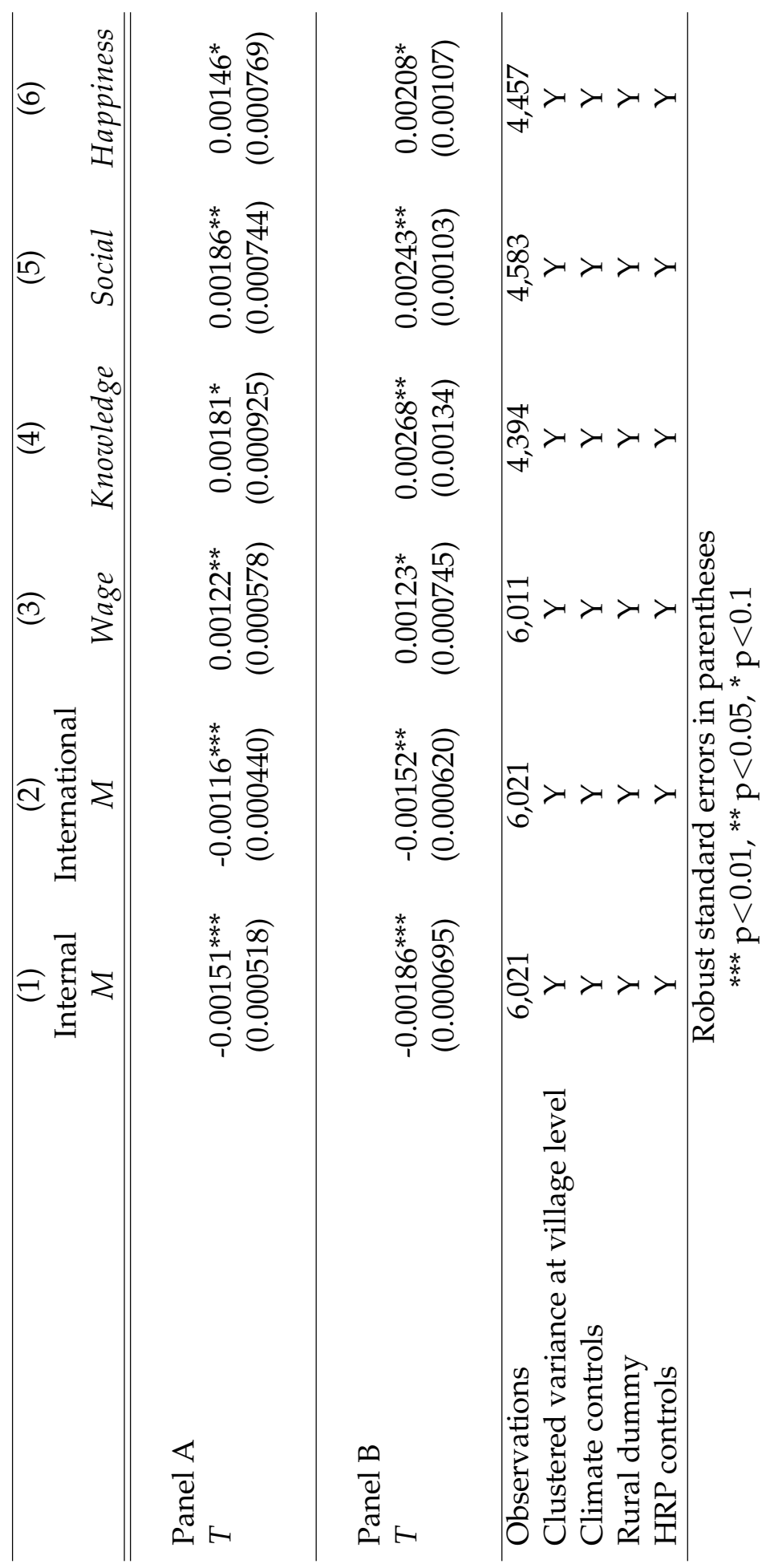

Notes: This table displays the estimated coefficients of running the second stage regression model, equation (3.2), for different outcome variables to study the channels leading to our findings. Data is at household level. Standard errors are clustered at village/ward level. 
Table 9: Perceived impacts of mobile phones (only those that used a mobile phone):

\begin{tabular}{ccc}
\hline \hline Do not improve (0/1) & Improve (0/1) & Do not know (0/1) \\
\hline
\end{tabular}

$\begin{array}{lccc}\text { Economic status } & 16 & 72 & 12 \\ \text { Knowledge } & 17 & 69 & 14 \\ \text { Social relationships } & 8 & 81 & 11 \\ \text { Emotional wellbeing } & 15 & 72 & 13\end{array}$

Note: The table reports the percentage of individuals that have used phones that believe mobile phones have improved their economic status, level of knowledge, social relations or emotional skills, did not improved them or do not know.

\section{References}

Aker, J. (2008). Does Digital Divide or Provide? The Impact of Cell Phones on Grain Markets in Niger. Working Papers 154, Center for Global Development.

Aker, J. and Mbiti, I. M. (2010). Mobile Phones and Economic Development in Africa. Working Papers 211, Center for Global Development.

Aker, J. C., Clemens, M. A., and Ksoll, C. (2011). Mobiles and mobility: The effect of mobile phones on migration in niger.

Aker, J. C., Collier, P., and Vicente, P. C. (2017). Is information power? using mobile phones and free newspapers during an election in mozambique. Review of Economics and Statistics, 99(2):185-200.

Andersen, T. B., Bentzen, J., Dalgaard, C.-J., and Selaya, P. (2011). Does the internet reduce corruption? evidence from u.s. states and across countries. World Bank Economic Review, 25(3):387-417.

Andersen, T. B., Bentzen, J., Dalgaard, C.-J., and Selaya, P. (2012). Lightning, IT Diffusion, and Economic Growth Across U.S. States. The Review of Economics and Statistics, 94(4):903-924.

Andrews, D. W., Moreira, M. J., and Stock, J. H. (2006). Optimal two-sided invariant similar tests for instrumental variables regression. Econometrica, 74(3):715-752.

Andrews, D. W., Moreira, M. J., and Stock, J. H. (2007). Performance of conditional wald tests in iv regression with weak instruments. Journal of Econometrics, 139(1):116-132. 
Chalk, P. (2009). Instruments of development: Randomization in the tropics, and the search for the elusive keys to economic development. NBER Working Papers 14690, National Bureau of Economic Research, Inc.

Ciacci, R. and Rascón, E. (2019). A Matter of Size: Comparing IV and OLS estimates. Working paper.

FINMARK (2013). Finscope survey myanmar. Technical report.

Hall, C. S., Fottrell, E., Wilkinson, S., and Byass, P. (2014). Assessing the Impact of mHealth Interventions in Low- and Middle-Income Countries - What Has Been Shown to Work. Global Health Action, 7.

Jensen, R. (2007). The Digital Provide: Information (Technology), Market Performance, and Welfare in the South Indian Fisheries Sector. The Quarterly Journal of Economics, 122(3):879-924.

Klonner, S. and Nolen, P. J. (2010). Cell Phones and Rural Labor Markets: Evidence from South Africa. Proceedings of the German Development Economics Conference, Hannover 2010 56, Verein fÃ¹/4r Socialpolitik, Research Committee Development Economics.

Manacorda, M. and Tesei, A. (2019). Liberation Technology: Mobile Phones and Political Mobilization in Africa. Econometrica, (10).

Moreira, M. J. (2003). A conditional likelihood ratio test for structural models. Econometrica, 71(4):1027-1048.

Muto, M. (2009). The impacts of mobile phone coverage expansion and personal networks on migration: evidence from uganda. Technical report.

Oster, E. (2017). Unobservable selection and coefficient stability: Theory and evidence. Journal of Business \& Economic Statistics, pages 1-18.

Roller, L.-H. and Waverman, L. (1996). Telecommunications Infrastructure and Economic Development: A Simultaneous Approach. CIG Working Papers FS IV 96-16, Wissenschaftszentrum Berlin (WZB), Research Unit: Competition and Innovation (CIG).

Shapiro, J. N. and Weidmann, N. B. (2015). Is the Phone Mightier Than the Sword? Cellphones and Insurgent Violence in Iraq. International Organization, 69(02):247-274.

World Bank (2015). Myanmar: Telecommunications Reform. Technical report, World Bank Group. 


\section{Appendix}

\section{A Myanmar}

Myanmar is a lower-middle income country ${ }^{7}$ with a GDP per capita of USD 1,204 in 2014. The country, ruled between 1962 and 2015 by a military council, experienced little economic growth during the last fifty years in comparison with other South-East Asian countries such as Vietnam, Thailand or Laos. Following five decades of state-led economy and little openness, Myanmar's economic and political institutions have been experiencing remarkable changes in the last years. For example, for the period 2012-2014 the average growth rate per year of the GDP was 7.3\%, two percentage points higher than the average growth rate for the period 2009-2011. International enterprises and organizations are increasingly settling in Myanmar and foreign direct investments (FDI) has boomed since the approval of a new Foreign Investment Law in 2012 that released most of legal constraints for foreign investments (Chalk, 2009).

World Bank data reveals an increase in foreign direct investments (FDI) in Myanmar between 2011 and 2015 of approximately 48\%. In the last four years, different laws were also approved liberalizing strategic economic sectors such as the banking sector and the currency exchange rate and releasing free many political opponents that were imprisoned. In November 2015 the National League for Democracy won the national elections defeating the military-supported government that ruled the country for more than 50 years. In this context of political transformation, growing openness and market-oriented institutions, the telecommunication sector was not an exception.

In October 2013 the Government of Myanmar passed a law to promote open competition and the liberalization of the telecommunication sector which was under the monopolistic control of the Myanmar national operator Myanmar Post and Telecommunications (MPT). Following the approval of this law, the government granted in January 2014 licenses to the international mobile phone operators Ooredoo and Telenor to operate in Myanmar.

\footnotetext{
${ }^{7}$ WB classification available at http://data . worldbank.org/country/myanmar
} 